\title{
Mehit's Stump: Unmasking the Great Sphinx of Giza
}

\author{
Robert S. Neyland \\ Independent Researcher, Breckenridge, CO, USA \\ Email: rob@breckenridgeassociates.com
}

How to cite this paper: Neyland, R. S. (2020). Mehit's Stump: Unmasking the Great Sphinx of Giza. Archaeological Discovery, $8,1-25$.

https://doi.org/10.4236/ad.2020.81001

Received: September 25, 2019

Accepted: November 4, 2019

Published: November 7, 2019

Copyright $\odot 2020$ by author(s) and Scientific Research Publishing Inc. This work is licensed under the Creative Commons Attribution International License (CC BY 4.0).

http://creativecommons.org/licenses/by/4.0/

\begin{abstract}
The current mainstream model of history proposes that $4^{\text {th }}$ Dynasty King Khafre had the Great Sphinx carved from the bedrock of the Giza Plateau in approximately 2500 B.C.E., and that the entire statue including its head, neck, and body was sculpted from the three raw substrate limestone layers of the Mokattam Formation de novo at the same time. However, a growing body of evidence suggests that the Great Sphinx is older than the date commonly ascribed to its construction, and that the head and neck were merely remodeled from a prior sculpture to create the face of the Great Sphinx sometime during the Old Kingdom. The following archaeo-sculptural analysis of the Great Sphinx subjects the monument to a detailed reconstructive examination to demonstrate the existence of a previously unreported contour signature, which suggests a modification to a prior sculpted structure that was partly removed and/or altered. This discovery provides a basis for an empirical method, which may aid in the relative dating of the stone layers belonging to the neck and body of the Great Sphinx to determine if they were indeed created at the same time or in different eras.
\end{abstract}

\section{Keywords}

Great Sphinx, Giza, Lioness, Mehit, $4^{\text {th }}$ Dynasty, Khafre

\section{Introduction}

Despite circumstantial archeological and Egyptological evidence dating the creation of the Great Sphinx to the Fourth Dynasty (Lehner \& Hawass, 2017: pp. 240-241), there is no unequivocally conclusive evidence when or by whom it was carved. Based on geological and astronomical evidence, some researchers have proposed that the monument was carved at an earlier date, and its head was merely re-carved in dynastic times (Dobecki \& Schoch, 1992; Schoch, 1992; Schoch \& Bauval, 2017). Textual evidence suggests that the monument was originally a 
lioness (Seyfzadeh et al., 2017; Seyfzadeh \& Schoch, 2018; Figure 1). An analysis and discussion of this evidence, pro and con, is outside the scope of this paper. However, it makes a testable prediction: if the head of the Great Sphinx was indeed re-carved from the head of an older, original lioness statue as proposed, a plausible sculptural reconstruction of the original monument must in principle demonstrate that all known sculptural elements present throughout its history, even if no longer existing, can be contained inside the original head and neck of the reconstructed lioness simulated in sculpture (Figure 2).

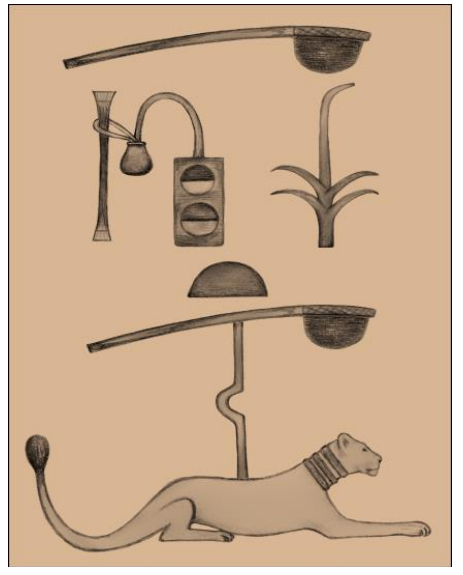

Figure 1. The tandem dual title mentioning Mehit as seen on the pedestal of Hemiunu, the slab stele of Wepemnefret, and the wooden tomb panels of Hesy-Ra: Overseer of the Scribes to the King and Master of the Key to the Lioness. Or: "The King's Chief Librarian and Guardian of the Royal Archives of Mehit." Image by permission of Catherine Ulissey and Robert Schoch.

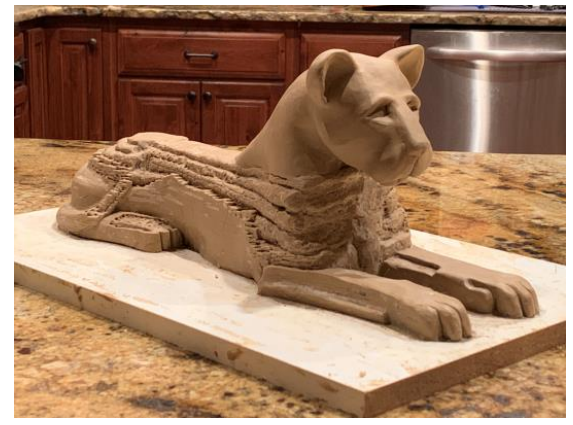

Figure 2. Reconstruction of the hypothetical lioness statue in sculpture. Sculpture and photo by R.S.N., May 2019.

Using historical and contemporary references (Lehner, 1991), photographs and descriptions from history (Hassan, 1953: pp. 234-268; Figure 3), photographs and visual inspections made in person when touring the site in May 2019, this is the purpose of the study I here present. My contribution to the debate about the age and construction of the Great Sphinx rests on a reconstructive analysis and interpretation of weathering and sculptural aspects of the shape-changing process which created it from its proposed origin as a lioness statue. This process involves the subtractive reduction of a multi-ton dense and brittle bedrock me- 
dium, i.e. the three-layered Mokattam Limestone Formation, into a desired sculptural result using only hand tools, which I here simulate.

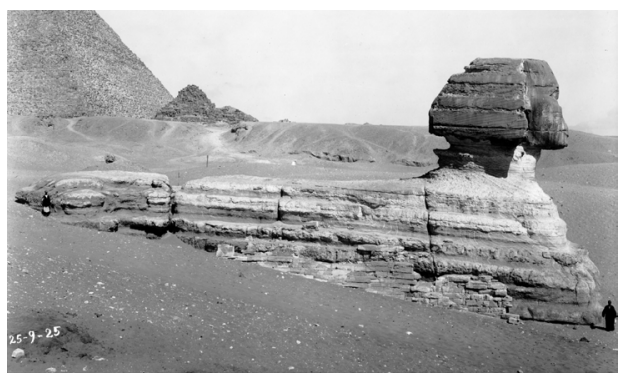

Figure 3. 1925 view of the Great Sphinx pre-restoration, before concrete repairs applied during Émile Baraize's excavation. The Major Fissure at hips of the statue is still visible, in addition to the crack directly behind the head. The front fissure possibly was created during the same impact which caused the royal Nemes tail to break off.

https://1drv.ms/u/s!AjLfhylwf90ogZcp8ENFEIN6aw81VQ

If the Great Sphinx we know today was indeed carved from an earlier lioness monument as proposed (Schoch, 2012: pp. 24-37; Seyfzadeh et al., 2017), the original "block" would be the lioness head into which everything sculpted later must fit. The lioness head, if it existed and unlike the current Sphinx head, must also be proportional with the original core body of the lioness monument. We must be able to work backwards to reconstructively incorporate all subsequent components of the Sphinx head. This does not just include the appearance of the currently existing head, but also known historical elements such as Nemes headdress and tail, the Sphinx's beard, and the breast lappets (Figure 4).

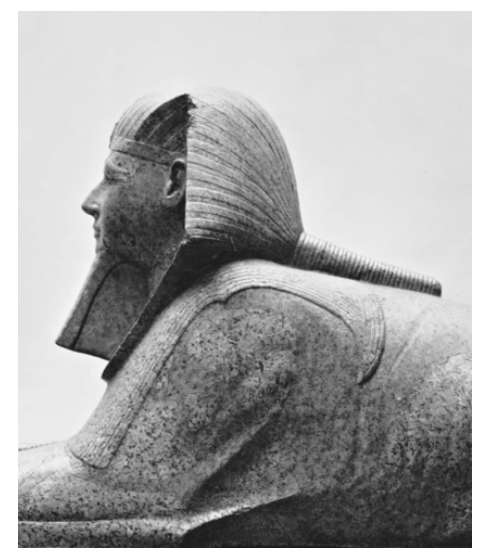

Figure 4. A reconstructive head must be able to include all known presented historical elements: royal Nemes headdress, tail, beard, breast lappets and a nose. From Lehner (1991). The Archeology of an Image: The Great Sphinx of Giza. Zenodo.

https://zenodo.org/record/1203621

By contrast, the Great Sphinx's core body was carved directly from the two lower strata of the Mokattam Formation of the Giza Plateau, and so the original "block" as it pertains to the Sphinx core body are the middle and lowermost Members II and I, respectively. 
There is no evidence today that other stony images of naturally wild or fable creatures ever existed over the currently known monument. Instead, geological evidence points to the Third Member (Member III) stratum's lone promontory from which the head was fashioned. "The Sphinx head layers are found nowhere else on the Giza Plateau." (Lehner, 1991: p. 16).

The first two forensic archaeo-sculptural aspects that present themselves are: 1) the existing head is clearly too small for the monument (e.g. Lehner, 1991: p. 347); and 2) the existing head is the least eroded and deteriorated component of the monument. It is still exhibiting crisply cut lines of the Nemes headdress, and devoid of the vertical and horizontal erosion striations characteristic of the rest of the monument's core body (Figure 5).

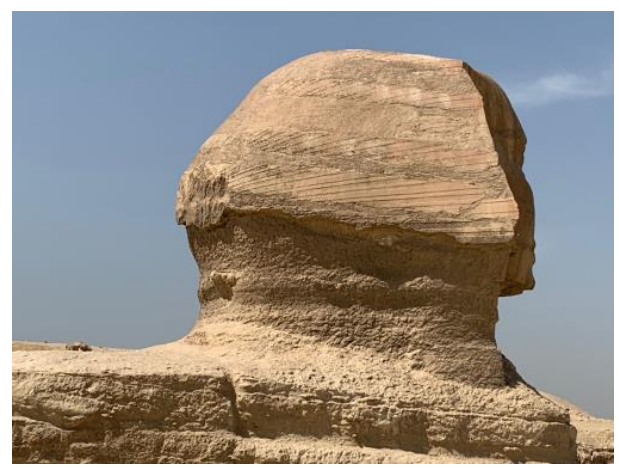

Figure 5. Converging Nemes headdress lines are still distinctly evident. Softer strata were filled in with concrete in 1926, during Émile Baraize excavation. The breakage scar at rear of head is clearly visible. Photo by R.S.N., June 2019.

Even though the head is comprised of the harder and denser Member III strata (Hawass \& Lehner, 1994a: pp. 47), it has been exposed to the elements since its creation, presumed to be in circa 2500 B.C.E., while the body has been largely buried in sand for millennia interrupted only by comparatively short periods of restorative excavations both in ancient and modern times (e.g. Thutmose IV, Roman era, Giovanni Caviglia, Auguste Mariette, Gaston Maspero, Emile Baraize and Selim Hassan) (Figure 6).

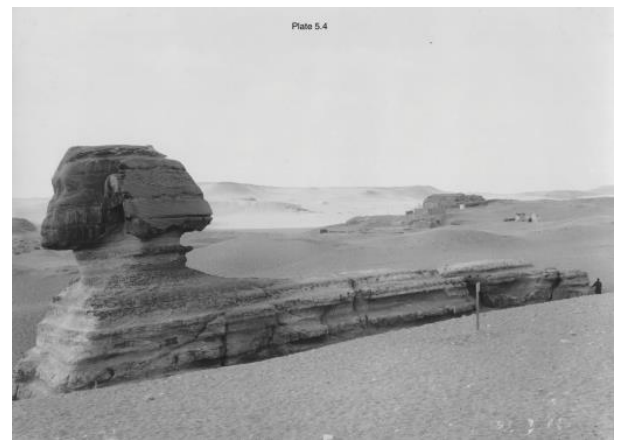

Figure 6. The Great Sphinx. Pre-reconstruction photo dated to 1925. From Lehner (1991). The Archeology of an Image: The Great Sphinx of Giza. Zenodo. https://zenodo.org/record/1203621 


\section{Methodology}

Various images of lioness heads available on the worldwide web were studied; these included photos of live animals as well as ancient iconography from Egyptian temples and the array of lion imagery which I observed displayed in the Cairo Museum (Figures 7-9). In order to demonstrate that all elements could fit inside a lioness statue's head and neck which was proportional with the body of the Great Sphinx, the existing monument had to be recreated first. Oil-based sculptor's clay, clay working tools, a sculptor's hands and eyes, the Internet, and a personal dawn visit to the Sphinx Enclosure were the tools utilized.

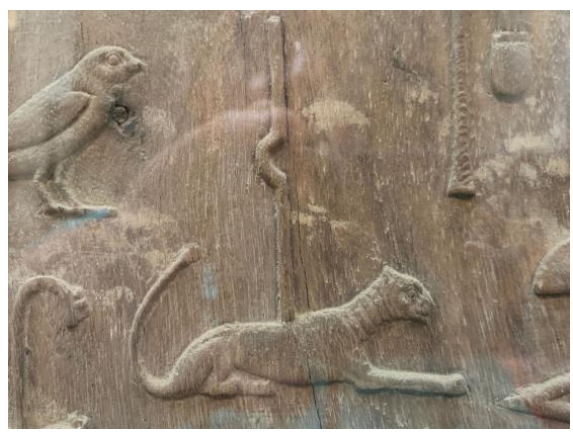

Figure 7. Mehit carving, with bent rod key in back from the wooden panels found inside Third Dynasty official Hesy-Ra's tomb at Saqqara, Egypt. The use of this image associated with the lion goddess Mehit extends back to early dynastic times. Cairo Museum. Photo by R.S.N., June 2019.

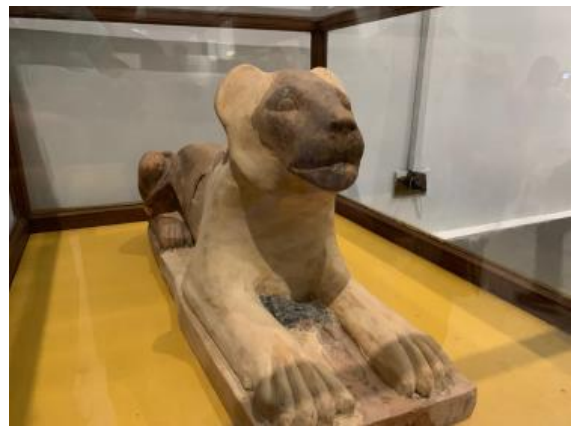

Figure 8. Couchant lioness statue discovered at "Lion Hill", Saqqara, Egypt. While some lion images appear to have a male's mane, often it is a representation of the gathered skin on lioness neck. Cairo Museum. Photo by R.S.N., June 2019.

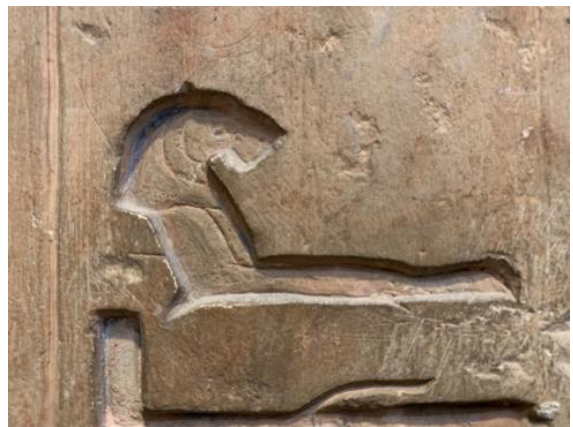

Figure 9. Split Lioness iconography. Cairo Museum. Photo by R.S.N., June 2019. 
There is no shortage of images of the Great Sphinx online, and I reviewed hundreds of them in every aspect to establish proportion, and to observe the cracks and erosion impacts. The multiple strata of the Giza bedrock presented rather like a layer cake, with each stratum taking on its own outline. As such, vertical top down images were most informative and helpful. The body layers and paws were sculpted first, followed by sculpting the existing undersized head. Then the cladding of the different historical "repair" areas was added all around the Sphinx body (Figure 10).

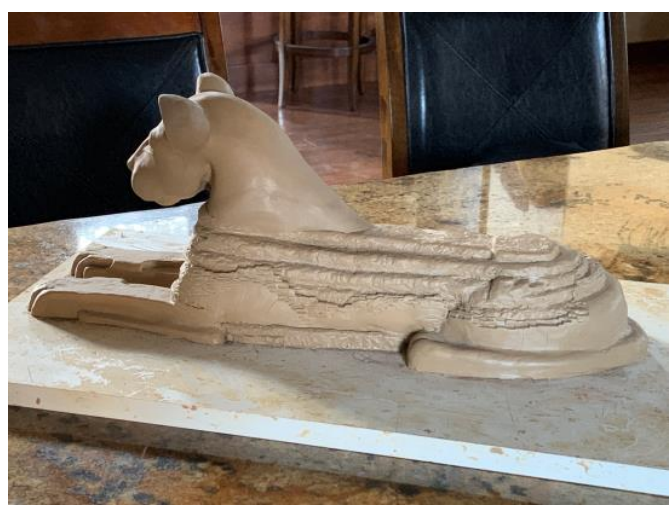

Figure 10. "Restoration" cladding added to Sphinx sculpture. Sculpture and photo by R.S.N., May 2019.

Once the current existing Sphinx was created, the lioness head was sculpted. The concept was to make the head much like a Godiva chocolatier: Mold the head to the desired configuration, slice it in half and hollow out the interior. Install the head pieces like a clamshell over the existing, undersized Sphinx head and examine the fit (Figure 11).

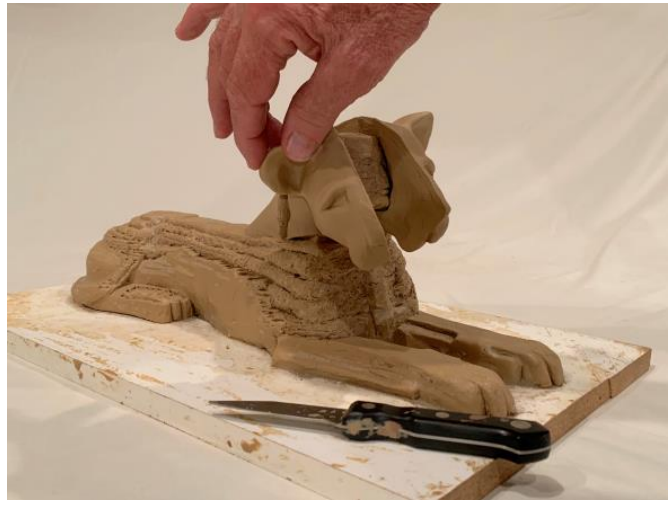

Figure 11. Clamshell head opening, like a chocolate truffle. The lioness head was sculpted last, then cut in half and hollowed out. Everything must fit inside. Sculpture and photo by R.S.N., May 2019.

The key aspect of the lioness head was the front to back placement upon the body. Studying scores of side views, front views and the few available, legible top views, I sought the correct proportions to the frontal chest, and the placement in 
relation to front elbows and rear paws. Specifically, my aim was to identify where the neck must have originally landed on the back of the monument to be correctly proportional. It should be noted that this sculpture does not purport to be an exact scale model in every detail; it is a study of proportion to demonstrate the concept of sculptural reduction.

\section{Results}

In a sculptural moment of coordinated tactile and visual observations, my hands and eyes arrived at the front-to-back landing area on my model which seemed to locate the proportionally correct place on the statue. There is a physical correlate on the Great Sphinx; it can be seen in an aerial photo as a faintly defined hump and the remnant of an eroded rock layer whose semi-elliptical shape and position on the back matches where one might expect a proportional lioness neck to once have landed on the back of the hypothetically remodeled Sphinx (Figure 12). Barely visible from the ground and in most views of the Great Sphinx, it appears only from above in the extreme late sunset light. What appears as silhouette of an elevated rock contour, is in fact a stratigraphic rise detailed in Lehner's topographic drawing (Lehner, 1991: Fig. 5.1; reproduced here as Figure 13). In that drawing it is shown as simply another contour line making up the lowest layer of the Member III stratum that comprises the Sphinx head. This was previously identified as Bed 7a in Lal Gauri's nomenclature applied to the substrata of the Member layers; in this scheme Bed 7a marks the thin, eroded boundary layer between the Sphinx's back and its head. Member II beds are numbered 1-6, with the softer beds labeled "i" and the harder beds labeled "ii". Gauri designates Bed 6ii as the top of Member II from which the body of the Sphinx was carved (Gauri, 1984: pp. 30-31; Lehner, 1991: pp. 198-200; Figure 14). Consequently, the Sphinx's head and neck belong to the limestone layers of the upper Member III, a limestone bed distinct from that of Member II (Lehner, 1991: p. 183).

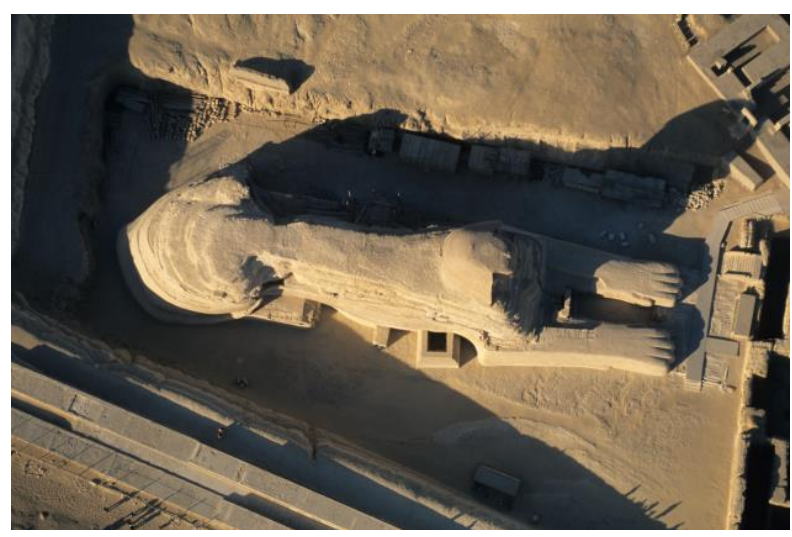

Figure 12. Aerial photo of the Great Sphinx taken during late sunset. The semi-elliptical stratigraphic rise is faintly visible only from the air in these extreme long-lighted conditions. Photo by Marcello Bertinetti, licensed use through Alamy.com \#IY01273732. February 2015. 


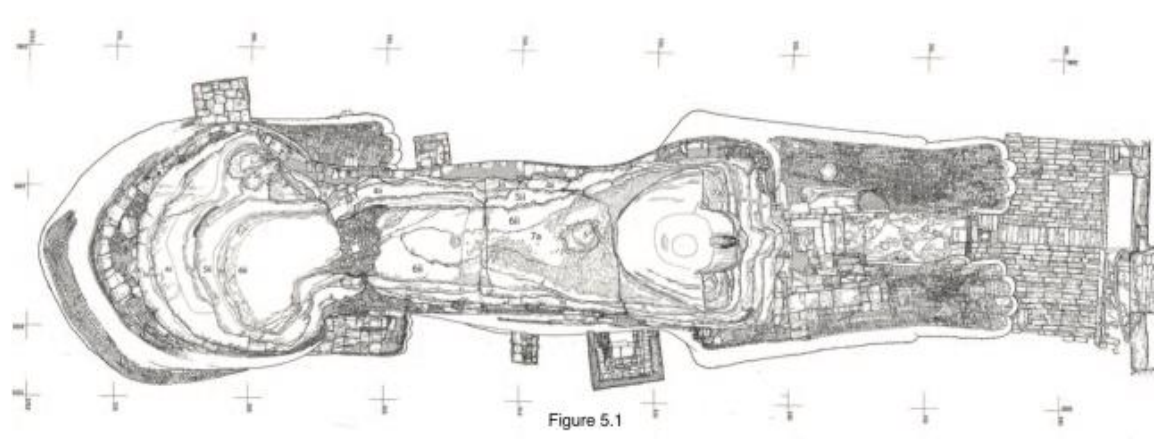

Figure 13. Illustration showing the location of Bed 7a. Courtesy of Mark Lehner. "Drawing d-ss-011 from Egypt/Giza/Sphinx Amphitheater/Sphinx Ditch/Sphinx Statue" (2017). In ARCE Sphinx Project 1979-1983 Archive. Mark Lehner, Megan Flowers, Rebekah Miracle (Eds.). Released: 2017-12-23. Open Context.

http://opencontext.org/media/b16d0723-802c-4141-97d0-b1b077678d2f

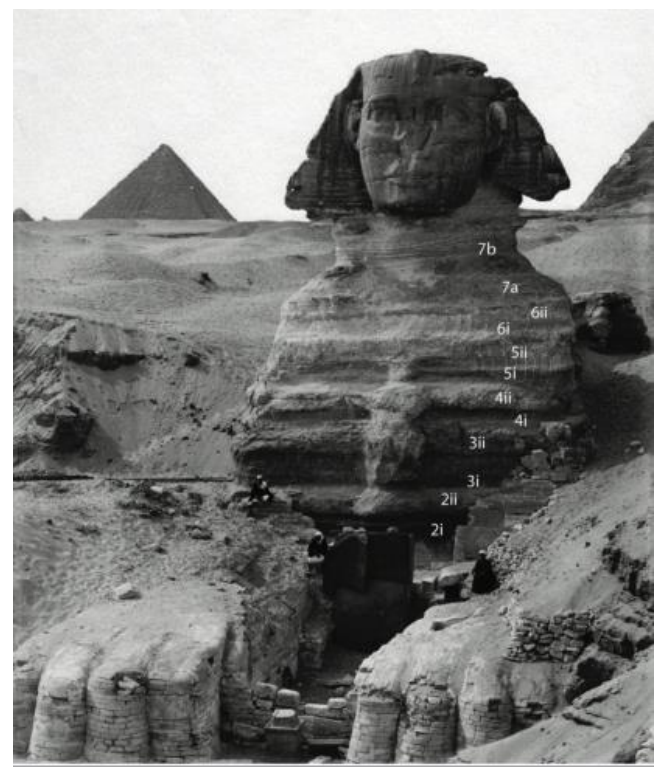

Figure 14. Member II Beds are numbered 1-6, with the softer Beds labeled "i", and the harder Beds labeled "ii". Gauri designates Bed 6ii as the top of Member II in the Sphinx body, and Bed 7a as the boundary layer between the Sphinx body and the neck. From Lehner (1991). The Archeology of an Image: The Great Sphinx of Giza. Zenodo.

https://zenodo.org/record/1203621

This topographic feature labeled $7 \mathrm{a}$ is consistent in size, shape, aspect and location with the remnant of a stump from the lioness neck's root. The cut-off stump constitutes an archaeo-sculptural signature (or "neck-print") left by the original sculpture from which a head and neck can be reconstructed that is proportional to the rest of the lion's body.

Lehner's contour drawings also show the location of the three major cracks/ fissures that transect the monument, particularly one which runs directly behind the head. This fissure was possibly caused by the same event which broke the ceremonial Nemes headdress tail (Schoch, 2012: pp. 173-179). This breakage event left a telltale scar on the rear of the Sphinx's head (Figure 15). 


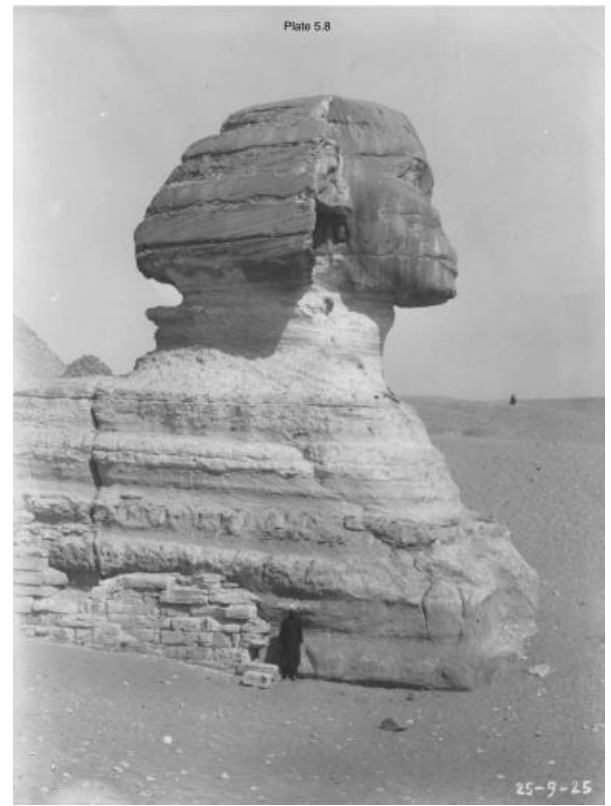

Figure 15. Pre-reconstruction photo from 1925 showing the frontal fissure vertically extending into the body of the Great Sphinx. From Lehner (1991). The Archeology of an Image: The Great Sphinx of Giza. Zenodo. https://zenodo.org/record/1203621

\section{Predictive Modelling}

Under the assumption that the lioness head was re-carved, trace sculptural remnants of prior versions can be reasonably expected, and these distinctions can be measured. This can be seen, for example, in the remnant lion ears and mane of the sphinx discovered at Abu Roash depicting Djedefre's sister-wife Hetepheres II (Figure 16).

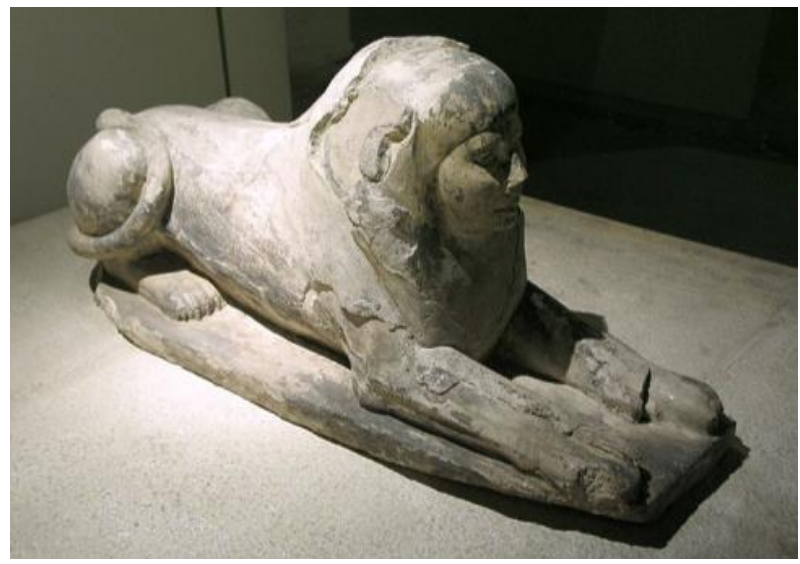

Figure 16. Sphinx statue of Djedefre's sister-wife Hetepheres II.

https://en.wikipedia.org/wiki/Hetepheres_II\#/media/File:Sphinx_of_Hetepheres_II_-_fou rth_dynasty_of_Egypt.jpg

Corroborating the remnant signatures of prior sculpted elements can allow predictive modelling to compare different rates and degrees of surface exposure, thermoluminescence, and weathering. If the current head was carved later than 
the core body, then the hump left from a previous neck described here would have been exposed to the elements for far less time than the back and rump of the Sphinx. This area identified as Bed $7 \mathrm{a}$ was not exposed as a surface until $\mathrm{c}$. 2500 B.C.E., when it was re-carved, and the old neck removed.

This "neck-print", or contour as shown by Lehner (Figure 17) provides a map that can precisely plot data points in proximity to adjacent Beds $7 \mathrm{a}$ and 6ii. One should be able to look for measurable difference in surface (or subsurface) exposure/weathering at these points in order to test the theory that the Great Sphinx's head and core body were not carved contemporaneously. The advantage of measuring relative weathering (not just erosion) of adjacent rock layers is that absolute dating is not required to draw a definitive conclusion, only differential weathering/surface exposure comparing one layer to the next. While the exact testing protocols likely remain to be identified, this archaeo-sculptural analysis provides a roadmap to predict such differences.

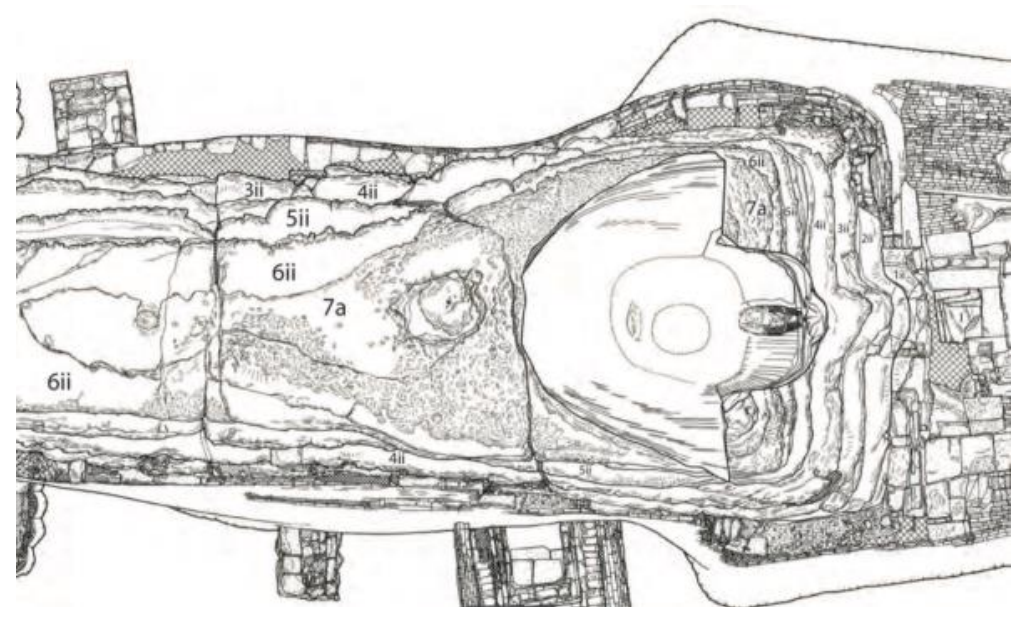

Figure 17. Illustration showing the limestone rock layer elevation contours as viewed from above. Layer 7a is sharply demarcated from layer 6ii defining the border between the head and neck of the Great Sphinx on the one hand and its body on the other. From Lehner (1991). The Archeology of an Image: The Great Sphinx of Giza. Zenodo. https://zenodo.org/record/1203621

\section{Discussion}

The initial objective of this sculptural examination was to demonstrate that if the head of the Great Sphinx was indeed fashioned from a prior image such as a lioness' head, then all the former's elements must be contained by the proposed lioness head under the assumption the original lioness body and head were created proportionally. I approached this strictly with the discipline imposed by the process of subtractive sculpture, using a sculptor's eye and reviewing hundreds of Sphinx images to gain a sense of this sculpture's proportions. The resulting sculptured model was not created to be an exact scale replica; instead, it served as a demonstration of concept. It was to be a work unbiased by observations and interpretations previously made by other researchers. Fortuitously, 
while creating the sculpture, I observed a hump which can in fact be seen in an aerial photo of the Sphinx taken at sunset (Figure 12). In order to assess the significance of this observation, I would like to first establish a context based on prior work.

Geology. "The Sphinx is cut from the lowest layers of the Mokattam Formation, those layers lying directly on the hard, petrified reef. Most of the lion body and south wall and the upper part of the ditch were carved in Member II, seven layers that are soft near the bottom and becoming progressively harder near the top. The neck is carved in the base of Member III, which is softer than the upper part from which the head is sculpted." (Hawass \& Lehner, 1994b: pp. 33-34; Figure 18).

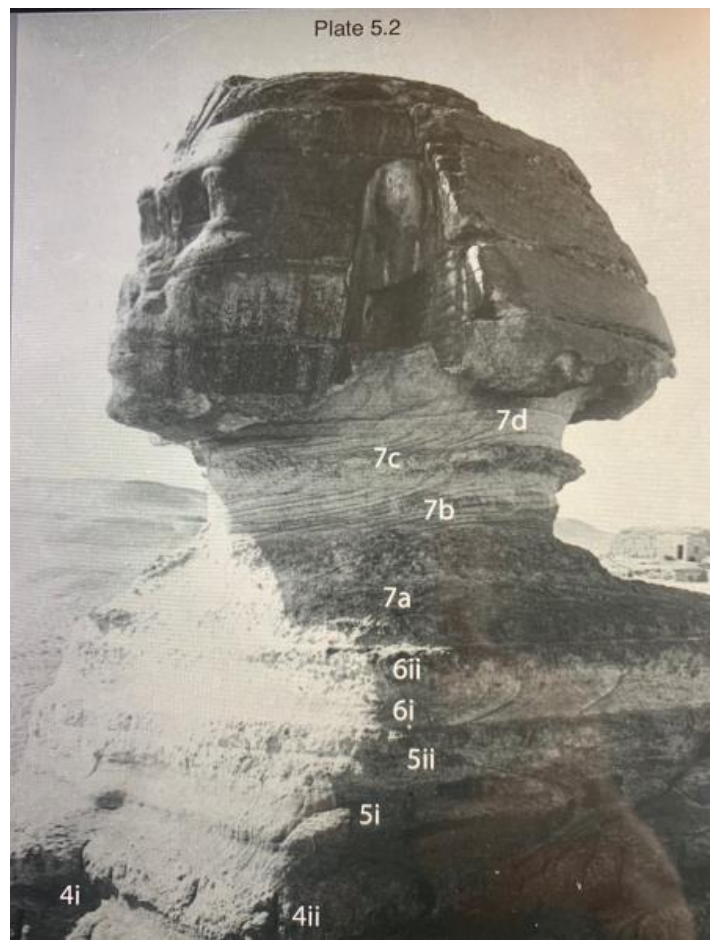

Figure 18. Gauri's nomenclature labelling the individual substrata of the Upper and Middle Members (III and II) of the Mokattam Formation as they contribute to the head, neck, and body of the Great Sphinx. From Lehner (1991). The Archeology of an Image: The Great Sphinx of Giza. Zenodo. https://zenodo.org/record/1203621

Member II beds are numbered 1-6 with the softer beds labeled "i" and the harder beds labeled "ii" (Gauri, 1984: pp. 30-31, Figures 3a-b). Lal Gauri designates bed 6ii as the top of Member II in the Sphinx body. Lehner further notes that Sphinx head layers are found nowhere else on the Giza Plateau (Lehner, 1991: p. 16).

No Prior References. No consensus exists on the conclusive date and sculptor of the Giza Sphinx as we know it:

"We are left to speculate about the meaning of the Sphinx for its builders because there are no known Old Kingdom texts that refer to it or its temple." 
(Hawass \& Lehner, 1994b: p. 35).

"Although we are certain that the Sphinx dates to the $4^{\text {th }}$ Dynasty, we are confronted by a complete absence of texts mentioning the Sphinx in the Old Kingdom." (Lehner, 1991: p. 95).

"None of the materials unearthed at Giza or anywhere else in Egypt make any mention of the statue's construction; it is referenced as though it had always existed when it is mentioned at all. It seems odd that so large and obviously significant a structure would not be mentioned anywhere by anyone at the time it was supposedly built." (Mark, 2016).

(Thutmose Stela) ... "This is the only text that makes a historical connection between Khafre and the Sphinx and here the connection, if any, is problematic..." (Lehner, 1991: p. 104). It would seem quite possible that the reason there is no mention of the Great Sphinx in Old Kingdom texts (see however Bauval's contention that its celestial counterpart was the Horakhty mentioned in the Pyramid Texts; Schoch \& Bauval, 2017: Chapter 6) is because it did not exist as a cultural image prior to the king carving his likeness into the head of a preexisting statue during the $4^{\text {th }}$ Dynasty, though this has been challenged recently (Seyfzadeh et al., 2017; Seyfzadeh \& Schoch, 2019). Certainly, there are 2500 years of Sphinx-styled iconography after that time, but as Lehner observes: “ $E_{X}$ cept for the Louvre head of Djedefre, no Nemes-coifed sphinx earlier than the Great Sphinx are known." (Lehner, 1991: p. 352; Figure 19). It should be noted here that the Djedefre head is conjectured to have been a part lion, part man sphinx image, although the altered image of his wife Heterphenes II may present the first appearance of recumbent lion with a human face.

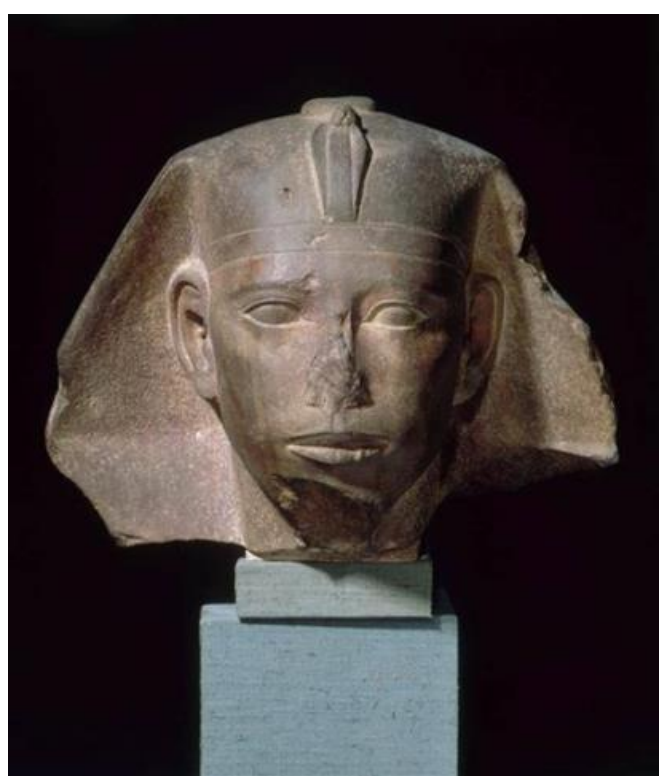

Figure 19. Quartzite sphinx head depicting King Djedefre, son of Khufu, Fourth Dynasty; Louvre, Paris, France. The familiar features of the Great Sphinx can be seen here: The Nemes headdress (unplaited here), the uraeus cobra head, and the intense stare.

https://www.louvre.fr/en/oeuvre-notices/head-sphinx-king-djedefre 
The sphinx design of an animal body and a human head with royal and divine features appears to be a later concept and was without precedent at the time of Khafre as noted by Lehner. It was not even called a Sphinx until 2000 years later when the name was applied by the Greeks. However, lion, lion goddess and couchant lioness imagery are profuse throughout Egyptian iconography dating well back to pre-dynastic times (Figures 20(a)-(c)), and these powerful female icons helped shape early culture (Seyfzadeh \& Schoch, 2019: pp. 12-13).

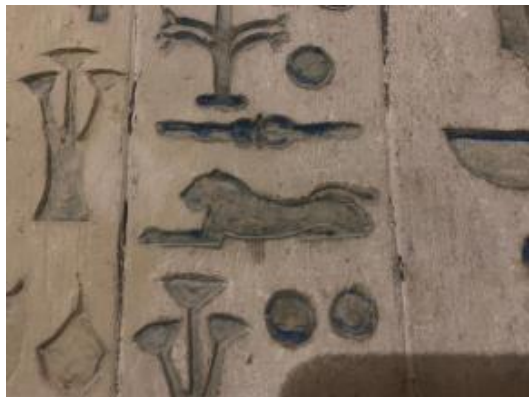

(a)

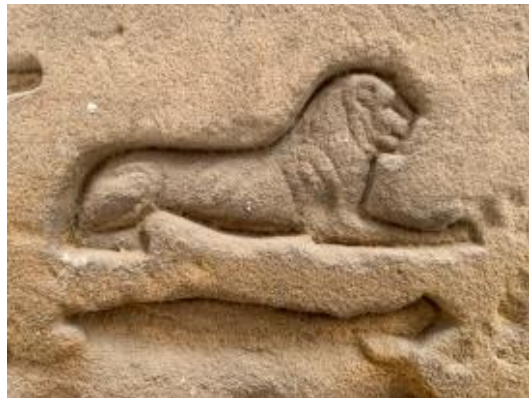

(b)

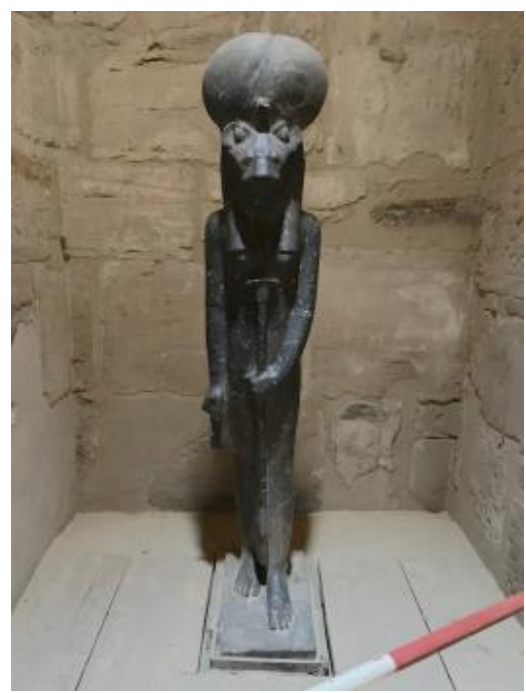

(c)

Figure 20. (a) Lioness symbol Saqqara, Pyramid of Unas, sarcophagus chamber, north wall. Photo by R.S.N., May 2019. (b) Lioness symbol inscribed into the Temple of Khnum at Esna. Photo by R.S.N., May 2019. (c) Statue of Sekhmet in a chapel of the Temple of Ptah at Karnak Temple, Luxor, Egypt. Photo by R.S.N., May 2019. 
Disproportionality. Much has been written of the disproportionate sizing of the Sphinx head relative to the lion body. It is variously attributed to miscalculation, structural constraints, material limitations, or the major fissures. Opinion varies widely on whether the head was carved first and then the body, or if the body was quarried first and the head articulated after.

From a sculptor's planning standpoint, if the head was carved from its promontory first, the quarrymen could have easily sized the body accordingly, and even would have the opportunity to move the body position forwards or backwards to accommodate the stone layers beneath. If the body was relieved from the Sphinx ditch first, then the head could easily be sized properly from the promontory material available. In short, if the head was first, they could have made the body smaller. If the body was first, they could have made the head larger when initially blocking the sculpture in. This combined with Lehner's insight that Khafre was a prolific statue builder, make the blunder scenario unlikely:

"It has not been appreciated the extent to which Khafre was the statue builder par excellence in the Old Kingdom. His reign is unequalled in terms of numbers and the great size of his statues until well into New Kingdom times." (Lehner, 1991: p. 107).

Geologist Colin Reader, likewise, rejects the blunder argument, and notes that the ancient Egyptians were masters in stonework and could not possibly have miscalculated in carving the Sphinx nor would they have shrunk the head out of proportion with the body for the sake of stability. There are plenty of other monuments, he notes, in perfect proportion, which have stood the test of time (Reader, 2001: pp. 149-159). Lehner concluded that Egyptians were carving smaller scale lions in the round since the First Dynasty, and in relief since the predynastic times, some of them reasonably accurate in their proportions (Lehner, 1991: p. 352).

Original Block? Lehner describes the original block of material that was sculpted into the Great Sphinx head as follows:

"The head itself must have been sculpted from a reserved block of limestone almost exactly $20 \times 20$ royal cubits square. Figure 9.1, in which the grid squares are each one royal cubit illustrates this point. In plan, the head is symmetrical with a fair degree of accuracy. The division of the face and the head into cubits corresponds remarkably with the upper hard layers of Member III bedrock, and even with the distinct beds into which Member II is subdivided." (Lehner, 1991: p. 348).

However, in Lehner's model of such an original block from which the head was carved, no allowances are made for other structures extending from the basic head design. While one can put a convenient grid box over a plan view of the current Sphinx's head as seen in his Figure 9.1 (Lehner, 1991: Figure 9.1; reproduced here as Figure 21), it omits all substrate material for the Nemes tail structure, the breast lappets, the uraeus, or the divine beard ... all of which must be incorporated into the head. Otherwise, those known elements would be "out of the block". That cannot be correct, except in the case of the divine beard, which may have been attached later. 


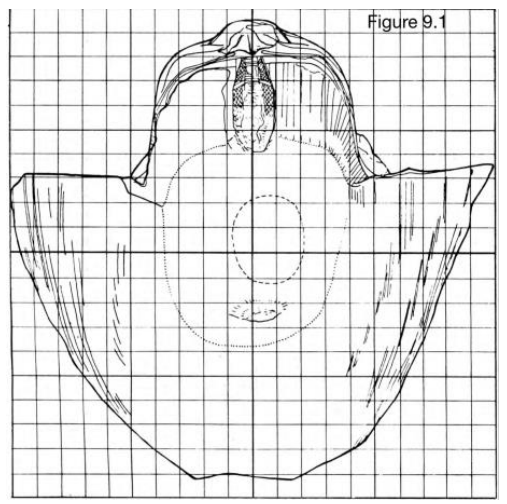

Figure 21. Hypothetical block from which the Sphinx head was carved according to Mark Lehner with superimposed grid. Each square is one royal cubit on the side. Image courtesy of Mark Lehner. "Drawing d-h-011 from Egypt/Giza/Sphinx Amphitheater/Sphinx Ditch/Sphinx Statue” (2017). In ARCE Sphinx Project 1979-1983 Archive. Mark Lehner, Megan Flowers, Rebekah Miracle (Eds.). Released: 2017-12-23. Open Context: http://opencontext.org/media/f21bca31-c2aa-4195-ad61-daa7ac19974c ARK (Archive): https://n2t.net/ark:/28722/k22z1g782

Lehner states that in sum, the head and the body are individually symmetrical, "and the front elevation is fairly well proportioned between head and body" (Lehner, 1991: p. 349). However, Lehner's Figure 9.4 shows an overlay of Khafre's head that does not align (Lehner, 1991: Figure 9.4; reproduced here as Figure 22). By contrast, the proposed lioness head brings proportionality to the statue and incorporates all the known historical elements of the head (Figure 23). This analysis allows the linking of the King to a $4^{\text {th }}$ Dynasty creation of the Sphinx. By carving his likeness into the head of the preexisting lioness monument, Khafre arguably created a previously unknown image which only after many centuries became known as the Sphinx.

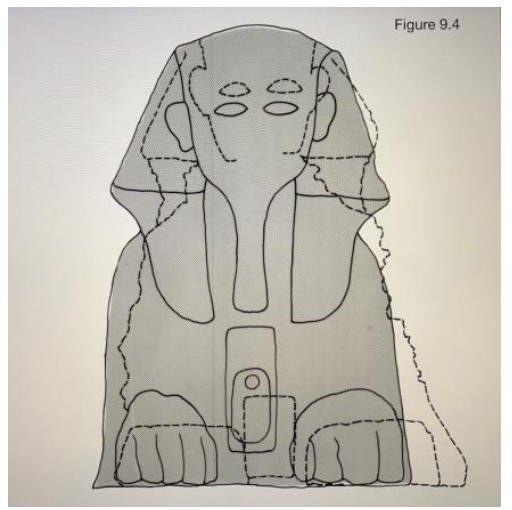

Figure 22. A hypothetical overlay. Lehner is seeking here to demonstrate that there is a reasonable match in proportion to the frontal contours of the existing Sphinx (dotted line) and the more traditionally proportioned Sphinx images of the $18^{\text {th }}$ Dynasty. Image courtesy of Mark Lehner. "Drawing d-ss-035 from Egypt/Giza/Sphinx Amphitheater/Sphinx Ditch/Sphinx Statue” (2017). In ARCE Sphinx Project 1979-1983 Archive. Mark Lehner, Megan Flowers, Rebekah Miracle (Eds.). Released: 2017-12-23. Open Context: http://opencontext.org/media/b03a6756-ad35-456b-978e-9546026a5e4f ARK (Archive): https://n2t.net/ark:/28722/k2sj1q92b 


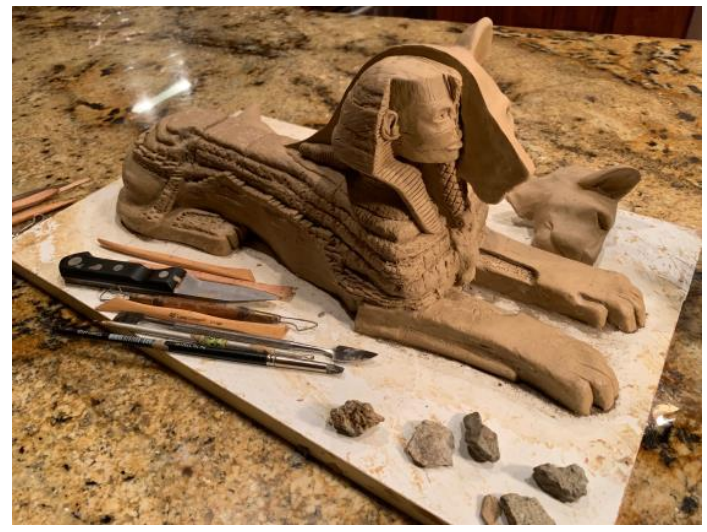

Figure 23. The proposed lioness head contains all historical elements within the boundaries of its contour. Sculpture and photo by R.S.N., August 2019.

Nemes Tail and Breast Lappets. As previously noted, the royal plaited Nemes headdress-clad sphinx is not known prior to the Great Sphinx. Certainly, there are over two millennia of Nemes-coifed sphinx images subsequent to the conventional creation date of the Great Sphinx. Any reconstruction of the historical Great Sphinx head must incorporate these essential elements of kingship, both the Nemes tail and the breast lappets (Figure 24). The crisply carved lines on the Sphinx head clearly gather at a convergence point at the rear of the head, although the height of this point is problematic for Lehner:

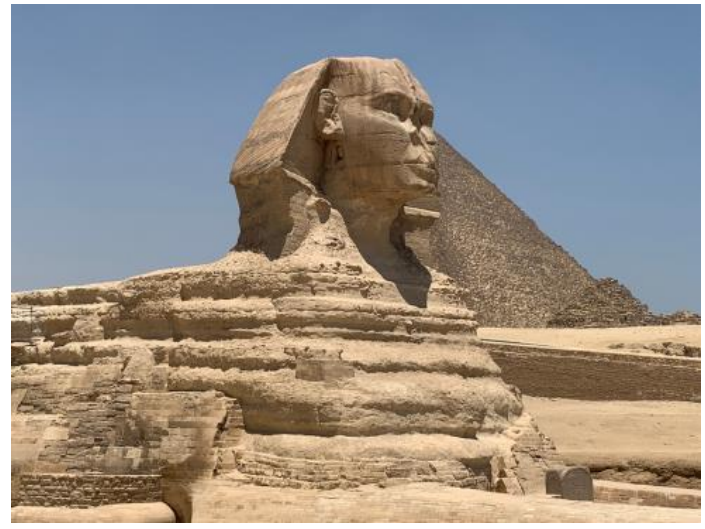

Figure 24. Modern visage of the Great Sphinx. The squared off shoulders Gauri described, which are thought to reflect bedrock remnants of breast lappets are visible on the near (south) side, as are the horizontal connectors where the lappets attached to the ceremonial headdress. Photo by R.S.N., June 2019.

"The tail of the Sphinx Nemes presents a puzzle, because the relief-carved pleating appears to be headed toward a knot that would have been 2.5 to $3 \mathrm{~m}$ above the top of the back ... but the break at the back of the head makes it likely that they carved the tail of the Nemes at least partly from the natural rock." (Lehner, 1991: pp. 357-358).

In the reconstructed model proposed here, the Nemes tail is gathered tight and low to acknowledge the breakage scar at the back of head (Figure 25). 


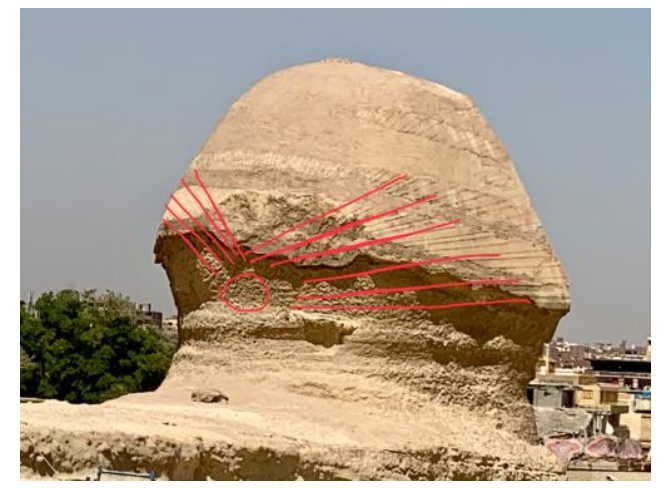

Figure 25. The original Nemes headdress lines are distinctly visible, note the lines converging low behind head. The telltale breakage scar is present at rear of head (see red circle). The softer, eroded strata of the head have been filled in with concrete during the 1925-36 Baraize restoration. Photo by R.S.N., June 2019.

Nemes Tail. Is the humped stratum behind the Sphinx head a connecting structure for the Nemes tail? While possible, the indicated convergence point for the carved lines on the Nemes headdress suggests an impractically elevated tail structure; almost 9 feet off the Sphinx back. From the sculptural planning and blocking standpoint, the Nemes tail either must be elevated on a substantial structure or lay along the back (as it does with virtually all other Sphinx images).

With the tail laying down along the back, there are only a few ways to visually elevate the tail. One is to make the gathered tail thicker to give the impression of height off the back. The other way is to elevate the entire surface beneath the tail. The difficulty with this approach is that it creates a giant visual structure to solve a small visual problem, creating a situation where the tail would take over the entire sculpture as the dominant visual element. Using the entire rock layer of Bed 7a spanning the width of the Sphinx back just to prop up the trailing Nemes tail a foot or so is not the kind of amateur planning mistake that the King's master quarrymen and sculptors would make in this monumental undertaking.

Given the problematic sizing of the King's head to lion body, either a larger, thicker Nemes tail or one that was raised on some elevated bridging would highlight and accentuate the disproportion, and possibly make a grotesque caricature out of the King's head. It would look like a small head with an over-sized stony blimp attached behind.

It is unlikely that its creators would use the entire breadth of the Sphinx back, and portions of strata $7 a, 7 b$ and $7 c$ only for the purpose of bridging for the Nemes tail, and that all evidence of this has eroded away. The Egyptians routinely carved in high relief, (such as arms, legs and beards) with solid bridging to the body, and this would be a more likely solution to which his sculptors would have turned.

These hypothetical scenarios suggest that the Great Sphinx as we see it today is the result of a series of blunders and miscalculations. That seems an inadequate assessment, given the extraordinary and timeless engineering and stonework performed all around the statue on the Giza Plateau (Reader, 2005: p. 54). 
The breakage of the Nemes tail structure may well have been associated with the eastern most fissure that transects the Sphinx directly behind the head. However, it may also have been vandalized or mutilated (perhaps along with the other symbols of divine kingship; beard, breast lappets).

Divine Beard. Fragments of a long, braided beard attributed to the Great Sphinx were found, and are displayed in the British Museum and Cairo Museum (Figure 26). Hawass and Lehner explain:

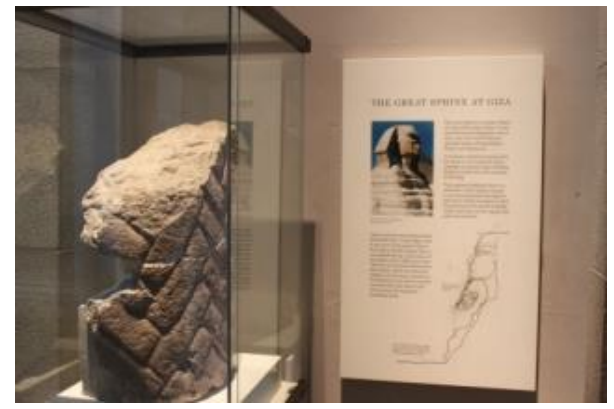

Figure 26. Remnant of the beard of the Great Sphinx, British Museum. https://danderma.files.wordpress.com/2010/12/ttdilvttbm24.jpg?w=570.

"The Sphinx Beard is relevant to this question. Captain Giovanni Battista Caviglia found several fragments of the beard at the base of the chest in 1817, the earliest recorded modern excavation of the Sphinx. The fragments were part of a long braided 'divine beard', curled at the end, that gods and deified kings wore. Statues of living kings sported short, square beard." (Hawass \& Lehner, 1994b: p. 37; Figure 27).

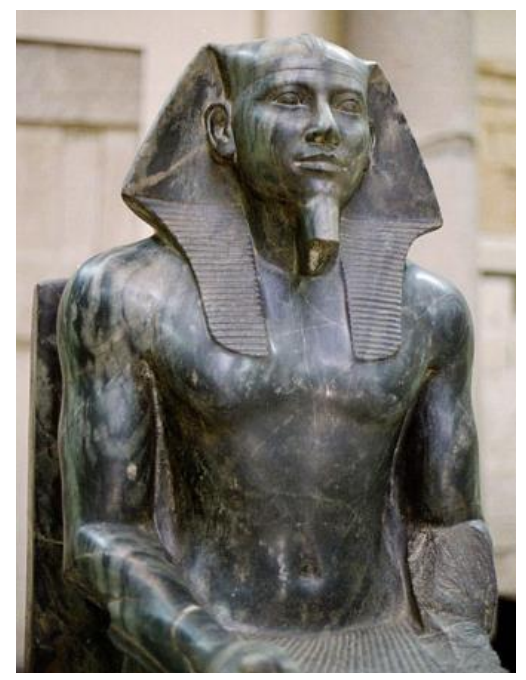

Figure 27. Khafre statue with royal beard, Cairo Museum. Photo by R.S.N., June 2019.

Evidence indicates that the beard was carved originally into the bedrock as a divine beard, not a royal beard:

"The long curled divine beard of the Sphinx appears to be the same stone as 
the layers of the Sphinx neck and chest where it once was positioned." (Lehner, 1991: p. 410).

Ricke maintains that the fragments show no evidence that the divine beard was adapted from a straight square royal beard (Ricke, 1970: p. 33).

Thus, the $4^{\text {th }}$ Dynasty carving created a Sphinx sculpture which began its life as a deified image, not simply an image of kingship. This raises the question if the king would have had his master quarrymen and sculptors create for the first time in history a unique image that was divine but diminutive? This seems unlikely. More likely is that the head became smaller because it had been re-carved from the weathered remains of a larger original. Even the braided, curled beard of divinity fits neatly into the modelled predynastic lioness head (Figure 28).

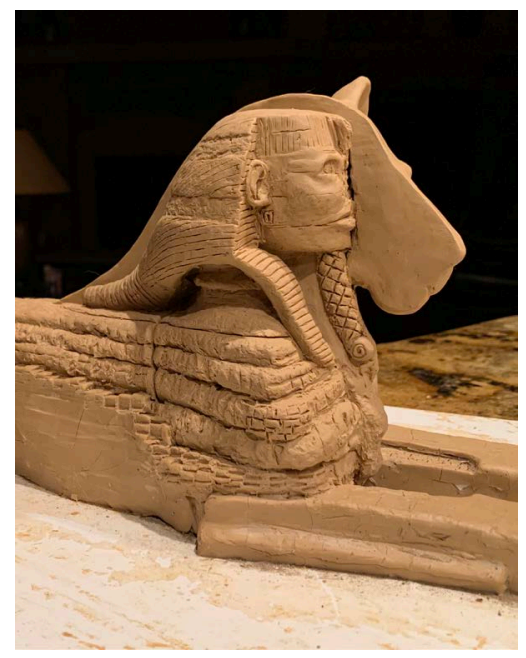

Figure 28. Divine beard fits into proposed lioness head. Sculpture and photo by R.S.N., August 2019.

Bed 7a. Lehner writes of the quarrymen who relieved the Sphinx from the bedrock:

"Their skill is evident in the way they fit their sculpture to the bedrock layers. They reserved the uppermost layers of the SE part of the Giza Plateau, Member III for the Sphinx's head ..." (Lehner, 1991: p. 408).

Bed $7 \mathrm{a}$ is one of the least discussed layers of the Sphinx structure, characterized mostly as a residual boundary layer between prominent strata, if mentioned at all.

As Lehner states:

"The neck consists of stone from geological beds $7 b, 7 c$, and $7 d$. Bed $7 c$ is slightly harder and was left protruding by the weathering away of $7 b$ and $7 d$." (Lehner, 1991: p. 198).

According to Gauri's distinction, the division between Members II and III occurs as a thin separation line passing through the upper, squared corners of the shoulders, about $3.5 \mathrm{~m}$ below the chin. Gauri designated Bed $7 \mathrm{a}$ as the beginning of Member III (Gauri, 1984: p. 31, Fig 3B; Figure 29). 


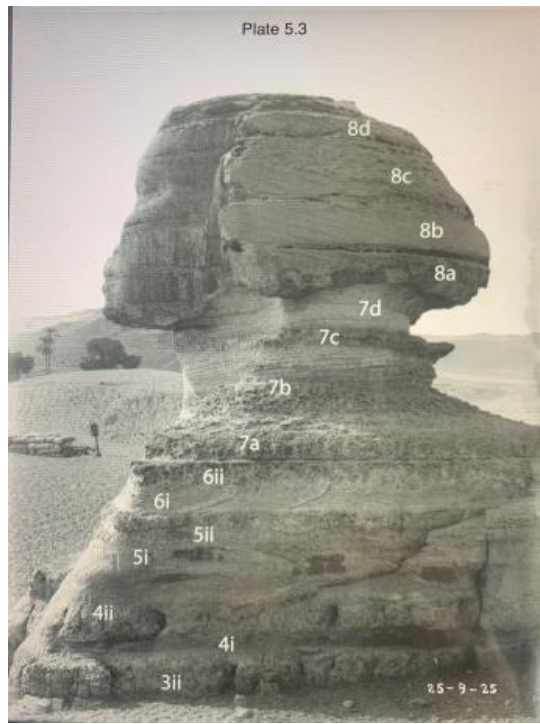

Figure 29. Pre-reconstruction photo from 1925 showing Gauri's designation of layers comprising the body, neck, and head of the Great Sphinx. The boundary layer between beds 6ii and 7a is sharply defined. From Lehner (1991). The Archeology of an Image: The Great Sphinx of Giza. Zenodo. DOI 10.5281/zenodo. 1203620.

Lehner describes the strata thus:

"The top of the Sphinx's back is mostly made from Bed 6ii (Member II) except for a residue of bed $7 \mathrm{a}$ (Member III), thinning out behind the head. Bed $7 \mathrm{a}$ is easily distinguished by the way it weathers, forming a dark crusty surface, as opposed to the smoother, more homogenous white and yellow beds of Member II. Bed 7a (Member III) can be traced from the top of the Sphinx's chest around the back of the head to phase out 15.0 m behind the neck." (Lehner, 1991: pp. 199-201; Figure 30).

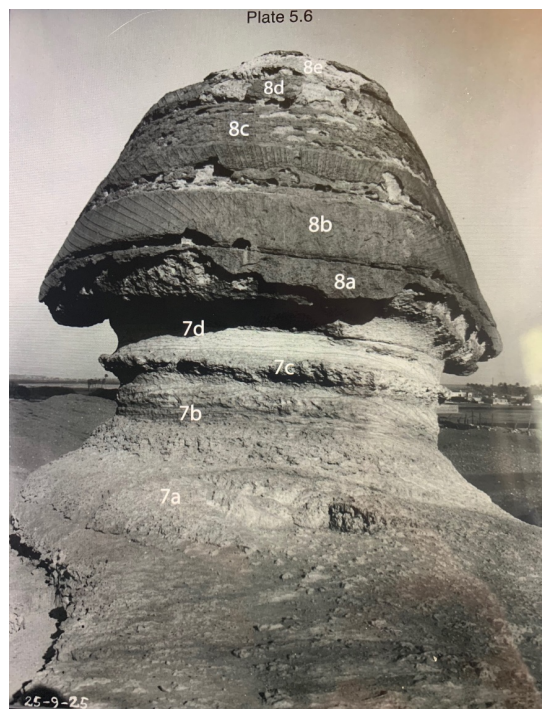

Figure 30. Bed 7a is a "residual eroded layer that thins out behind the head." Image courtesy of Mark Lehner. From Lehner (1991). The Archeology of an Image: The Great Sphinx of Giza. Zenodo. https://zenodo.org/record/1203621 
The presence of Bed 7a is delineated as a contour profile in Lehner's careful drawings of the topography of the Sphinx and is repeatedly described as the boundary layer between the Sphinx back and neck. All these descriptions and characterizations of Bed 7a appear correct. Geologically, it is the boundary layer between Member II and Member III. Sculpturally, the semi-elliptical mounded shape behind the Sphinx's head formed by Bed $7 \mathrm{a}$ is the boundary between the Sphinx's back and the root of the original lioness' neck. The "thinned out, residual layer" corresponds precisely in size, shape, aspect and location to where the root of the lioness' neck would have originated (Figure 31). Thus, while Bed 7a was described, it was incompletely interpreted. Bed 7a, arguably, is the key feature which identifies the substrate statue from which the Great Sphinx was made; this key feature was the root of the stony lioness's neck, which can incorporate all the subsequent historical sculptured elements of the Great Sphinx: Nemes tail, divine beard and breast lappets (Figure 32). Further, the reconstructed head of the monumental lioness incorporating all these elements makes the entire monument a proportional statue without the need to invoke the other explanations offered which rest on presumed mistakes, miscalculations and oversights by its creators (Figure 33 ).

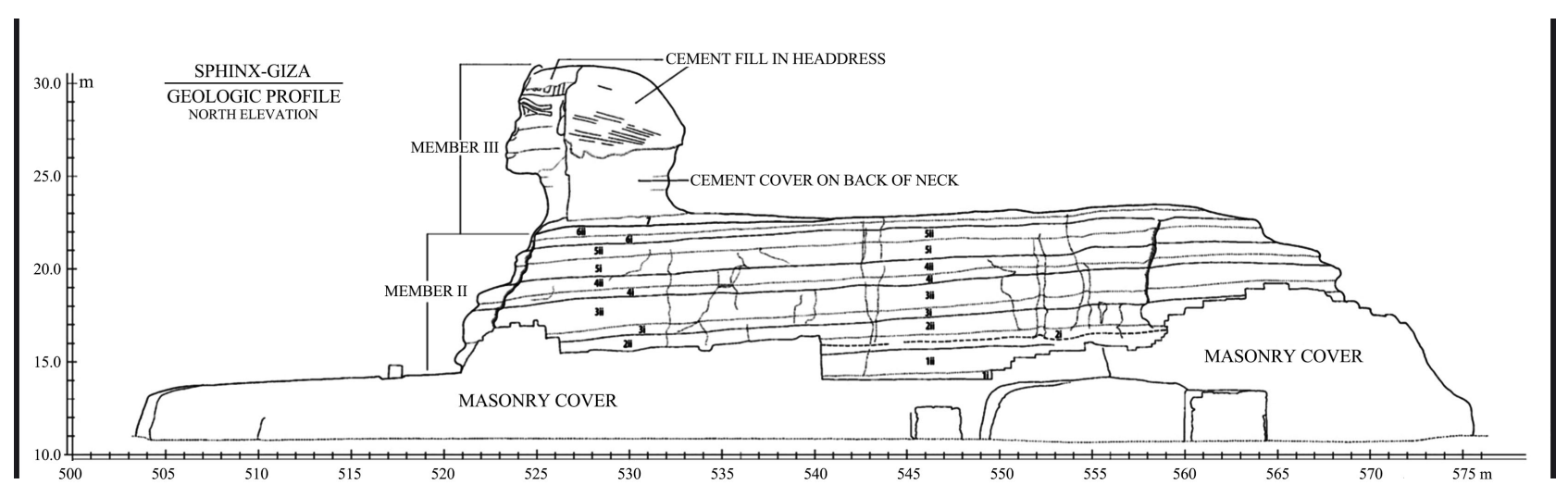

Figure 31. Bed 7a shown, but not interpreted. Image courtesy Mark Lehner. "Drawing d-ss-029 from Egypt/Giza/Sphinx Amphitheater/Sphinx Ditch/Sphinx Statue” (2017). In ARCE Sphinx Project 1979-1983 Archive. Mark Lehner, Megan Flowers, Rebekah Miracle (Eds.). Released: 2017-12-23. Open Context: http://opencontext.org/media/d1d1f1e6-87bd-4fc7-9f82-19d3d35eb47a ARK (Archive): https://n2t.net/ark:/28722/k2vm4gg5k

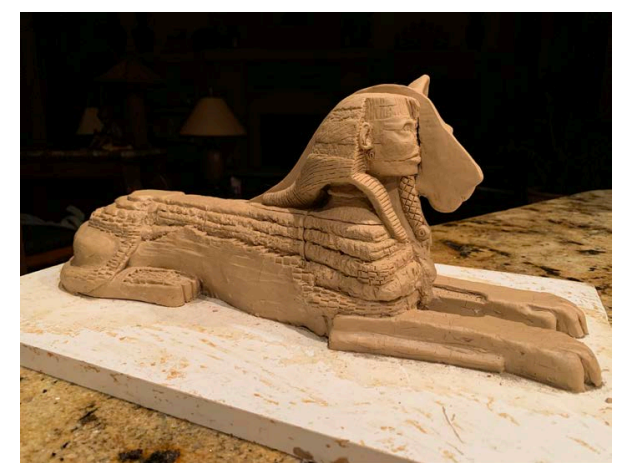

Figure 32. All Historical elements fit inside the proposed original lioness head. Sculpture and photo by R.S.N., August 2019. 


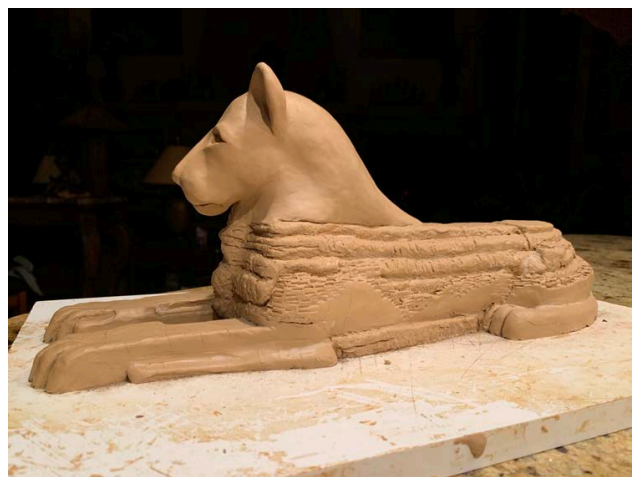

Figure 33. The proposed original sculpture of Mehit before losing her head. Sculpture and Photo by R.S.N., May 2019.

The model presented here makes a testable prediction. The boundary division between Bed 6ii and Bed 7a is well-mapped and provides a reliable guide for adjacent data points used to measure differential exposure/weathering. The exposure differential postulated here is by design more than a comparison of erosional weathering. Certainly, different layers of Member II and Member III comprise strata with varying hardness as has been well documented, and differing rates of simple erosion could be expected. Exposure sensitive markers must be identified which will reliably indicate differing degrees of cumulative surface and subsurface effects. Such markers are likely to present as accumulative of a molecular process, radiometric decay of certain isotopes or compounds, or the physiochemical transformation of isotopes which can provide a basis for comparison of similar stone surfaces independent of simple erosion.

All this natural stone material is photoreactive to some degree; witness the descriptions of the "natural patina" that forms on Member III. Not unlike a radiation dosimeter, there will be a cumulative difference in exposure demonstrated between the exposed surface of Bed 6ii and the much more recently revealed surface of Bed 7a. This surface was exposed circa 2500 B.C.E. when the neck was carved away by Khafre's sculptors as the head was re-carved to its current likeness. These quantifiable measurements may provide evidence that the Great Sphinx body and head are not contemporaneous. The hump could be a stump!

\section{Conclusion}

The preceding archaeo-sculptural analysis provides a roadmap to predict and establish an empirical method to confirm prior sculptural elements on the Great Sphinx of Giza and demonstrates that:

1) A proportional lioness head can spatially contain all subsequent sculptural elements historically displayed by the Great Sphinx.

2) There is a previously unreported "forensic neck-print" which is the contour signature of an alteration which reduced the lioness' neck at the time of re-carving, possibly to fashion the Nemes tail. If the hump was indeed the root of the original neck, the entire statue would have been proportional. Thus, the 
hump could be a remnant stump!

3) This new model of the evolution of the disproportionate Great Sphinx from a preexisting proportional lioness statue predicts that the original neck area (Bed 7a) and the contiguous back and rump (Bed 6ii) have been exposed to different time-dependent degrees of weathering due to sun, radiation, wind, sand, and rain; and these differences may be measurable to put the model to the test.

Sculpture is a primary modality of sub-verbal communication for cultures that generally predates written symbology. As a vehicle for expressing the cosmology and aspirations of ancient peoples, it can provide a unique window to learning about their beliefs. This is especially true when the effects of reuse, repurposing or appropriation can be identified as markers of the change and evolution of cultures. Archaeo-sculptural analysis may provide a useful tool for looking at other monuments in antiquity through the lens of sculpture and stone working. Examples include the adjacent Sphinx Temple and Valley Temple of Khafre, ostensibly comprised of stone quarried from the Sphinx Enclosure.

The conclusions presented here indicate that the existing head and core body of the Great Sphinx were not carved at the same time. Confirmation of this prediction through exposure sensitive markers will mean that the creation of this iconic statue must be ascribed to a different author, and to a different era than is commonly accepted. This in turn will require a re-examination of our understanding of the chronology and sequencing for the unfolding of the entire Giza Plateau. It impacts the Who, What, When, How and Why of the complex, with rippling implications for the advent of predynastic civilization in Egypt.

\section{Acknowledgements}

I thank the Organization for the Research of Ancient Cultures (ORACUL) for logistical research support while in Egypt. I thank the Egyptian Ministry of Antiquities for allowing access to the Sphinx Enclosure, the Osireion, and various areas at Edfu Temple. I thank Mr. Mohamed Ibrahim for logistic help while in Egypt. Sincere thanks to Dr. Manu Seyfzadeh for helpful discussions and reviewing the manuscript.

\section{About the Author}

My qualifications in this regard are unique; having competed around the world as part of the United States Snow Sculpture Team. Over the past 30 years I have been World Champion, US Champion, and have won numerous Gold and Silver Medals in international competition including Finland, Moscow, Sapporo Japan, and Breckenridge Colorado. These international competitions involve rendering a 25-ton frozen block into a finished sculpture in four days using only hand tools (Figures 34-36). As such, I am keenly aware of the dynamics of the subtractive process and working within the confines of the original "block" of material to achieve the desired sculptured result where extra material cannot be added back on. 


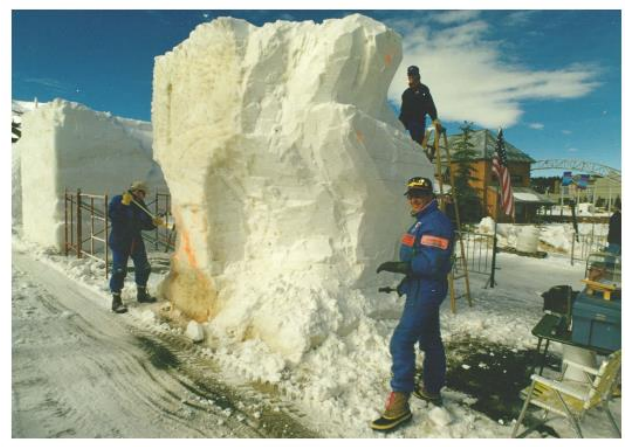

Figure 34. Early on Day 2 of "The Dance". 25-ton block, during four days, more than half will be removed by hand. The inner form is just beginning to emerge. Photo by D. Neyland, January 1998.

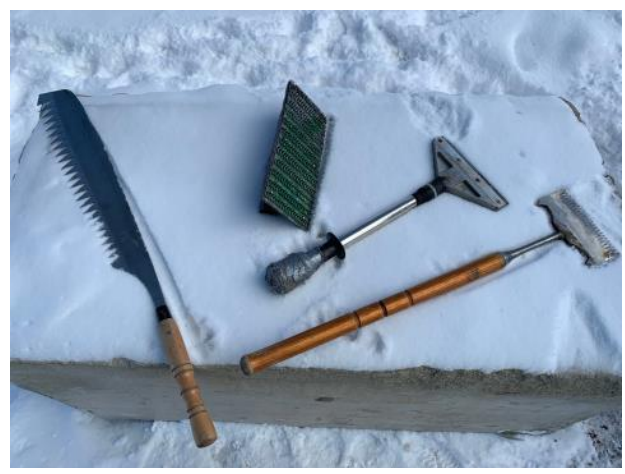

Figure 35. Hand Tools. They haven't changed much over the millennia: saw, chisel, scraper, tined fork ... except that today we can enjoy the magnificence of Japanese tool steel for the blades. Photo by R.S.N., January 2019.

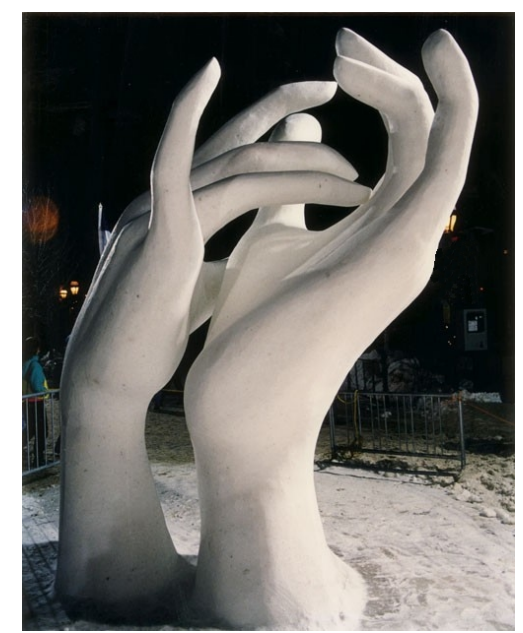

Figure 36. The Dance completed. 14 feet tall, hands not touching, completely self-supporting. Sculpture and photo by R.S.N., 1998.

\section{Conflicts of Interest}

The author declares no conflicts of interest regarding the publication of this paper. 


\section{References}

Dobecki, T. L., \& Schoch, R. M. (1992). Seismic Investigations in the Vicinity of the Great Sphinx of Giza, Egypt. Geoarchaeology: An International Journal, 7, 527-544. https://doi.org/10.1002/gea.3340070603

Gauri, K. L. (1984). Geologic Study of the Sphinx. NARCE, 127, 24-43.

Hassan, S. (1953). The Great Sphinx and Its Secrets. Historical Studies in the Light of Recent Excavations. Cairo: Government Press.

Hawass, Z., \& Lehner, M. (1994a). Remnant of a Lost Civilization? Archeology, 47, 44-47. http://www.jstor.org/stable/41766475

Hawass, Z., \& Lehner, M. (1994b). The SPHINX: Who Built It, and Why? Archeology, 47, 30-41. http://www.jstor.org/stable/41766473

Lehner, M. E. (1991). Archaeology of an Image: The Great Sphinx of Giza. PhD Thesis, Volume 1 (Text), New Haven, CT: Graduate School of Yale University.

Lehner, M., \& Hawass, Z. (2017). Giza and the Pyramids. The Definitive History. Chicago, IL: University of Chicago Press.

Mark, J. J. (2016). The Great Sphinx of Giza. Ancient History Encyclopedia. https://www.ancient.eu/Great_Sphinx_of_Giza/

Reader, C. (2001). A Geomorphological Study of the Giza Necropolis with Implications for the Development of the Site. Archeometry, 43, 149-159.

https://doi.org/10.1111/1475-4754.00009

Reader, C. (2005). A Reconciliation of the Geological and Archaeological Evidence for the Age of the Sphinx and a Revised Sequence of Development for the Giza Necropolis. In A. Cooke, \& F. C. Simpson (Eds.), Current Research in Egyptology II (pp. 47-56). Liverpool, Dublin: Bar International Series 1380.

Ricke, H. (1970). Der Harmarchistempel des Chefren in Giseh (pp. 31-33). Beiträge BF 10. Mainz: Rheingold Druckerei.

Schoch, R. (1992). Redating the Great Sphinx of Giza. KMT, a Modern Journal of Ancient Egypt, 3, 52-59, 66-70.

Schoch, R. M. (2012). Forgotten Civilization: The Role of Solar Outbursts in Our Past and Future. Rochester, VT: Inner Traditions.

Schoch, R. M., \& Bauval, R. (2017). Origins of the Sphinx: Celestial Guardian of PrePharaonic Civilization. Rochester, VT: Inner Traditions.

Seyfzadeh, M., \& Schoch, R. M. (2018). The Inventory Stele: More Fact than Fiction. Archaeological Discovery, 6, 103-161. https://doi.org/10.4236/ad.2018.62007

Seyfzadeh, M., \& Schoch, R. M. (2019). Major Geological Fissure through Prehistoric Lion Monument at Giza Inspired Split Lion Hieroglyphs and Ancient Egypt's Creation Myth. Archaeological Discovery, 7, 211-256. https://doi.org/10.4236/ad.2019.74011

Seyfzadeh, M., Schoch, R. M., \& Bauval, R. (2017). A New Interpretation of a Rare Old Kingdom Dual Title: The King's Chief Librarian and Guardian of the Royal Archives of Mehit. Archaeological Discovery, 5, 163-177. https://doi.org/10.4236/ad.2017.53010 